\title{
We All Need WE: The Effect of Using Facebook and Group Fieldwork on Students' Interdependence and Awareness of STSE Issues
}

\author{
Wafaa Mohammed Moawad Abd-El-Aal ${ }^{1} \&$ Astrid Steele $^{2, *}$ \\ ${ }^{1}$ Faculty of Education, Beni-Suef University, Egypt \\ ${ }^{2}$ Schulich School of Education, Nipissing University, Canada \\ *Correspondence: Schulich School of Education, Nipissing University, 100 College Drive, Box 5002, North Bay, \\ ON P1B 8L7, Canada. Tel: 1-705-474-3450 ext. $4043 \quad$ E-mail: astrids@nipissingu.ca, \\ wafaa.moawad@edu.bsu.edu.eg
}

The research was conducted at Beni Suef University, Egypt.

Received: January 11, $2017 \quad$ Accepted: January 28, $2017 \quad$ Online Published: February 17, 2017

doi:10.5430/wje.v7n1p53 URL: http://dx.doi.org/10.5430/wje.v7n1p53

\begin{abstract}
In a departure from traditional lecture formats, this research examines the effect of using both Facebook and group fieldwork in developing Egyptian pre-service teachers' interdependence, and their awareness of STSE. Group work and fieldwork were found to enhance interdependence/cooperation of participants, as well as strengthen their understanding of STSE issues. Participants found it difficult to find a balance between the different perspectives afforded by STSE studies. A number of recommendations are offered to strengthen teacher preparation in an Egyptian context.
\end{abstract}

Keywords: STSE; pre-service teachers; STSE awareness; interdependence

\section{Introduction}

In Egypt, pre-service teachers (PTs) preparing for their careers in faculties of education tend to be taught in traditional lecture formats. In the area of science education, PTs are rarely provided opportunities for active learning, group work, or discussion, nor do they use social media for educational purposes. Moreover, they are not often presented with occasion to critique the relationships between science, technology, society and environment (STSE). Given the direction of science teaching and learning in a global context, wherein students are encouraged to participate in science activities in groups, and in which STSE issues are becoming important components of a science education, the teacher training of PTs in Egypt may consider modification.

\section{Literature Review}

The literature review addresses four areas that inform and impact our research and writing: curriculum orientations that drive pedagogy, the current status of social media as a tool for teaching/learning in Egypt, an overview of STSE as it is currently understood, and specifically its position in science education in Egypt.

\subsection{Curriculum Orientations}

We take as our conceptual framework the curriculum orientations put forward by Miller and Seller, (1990) that describe three approaches to pedagogy: transmission, transaction and transformation. While other pedagogical and curricular frameworks exist, this model provides clarity to the teaching and learning context for our research.

Transmission is regarded as a traditional approach in which the learner remains passive, receiving information as decided upon and provided by a 'superior'. It is a teacher-directed approach, often enacted through lecture format. Freire referred to this as a banking model (1990), reductionist in nature, breaking content into small bits, or fragments, to be deposited with the learner. Indeed, the transmission orientation suggests that the world can be understood mechanistically (Hutchison \& Bosacki, 2000) - that is, it is the sum of its parts. Cervatiue and Ricento (2012) suggest that transmission perpetuates existing social and education structures. It is an orientation considered useful for transmitting facts, skills and values (Stanberry \& Azria-Evans, 2001), however, they point out that the 
information has to be meaningful to the audience, and be presented such that the students can relate to and organize it based on prior knowledge. The transmission orientation encourages memorization, rather than understanding and internalization, because learners are not required to critique the material presented against authentic contexts (ibid.). The transmission orientation is not generally suited to critiquing issues and problem solving (Russell, 1997).

The transaction orientation supports the learner as an active participant in constructing knowledge and developing skills, through interactions with resources, educators and other learners (Cervatiue \& Ricento, 2012). It has connection to constructivist learning (Hutchison \& Bosacki, 2000), recognizing the learner as an individual who brings personal experiences to the learning process (Russell, 1997). The transaction orientation focuses on the cognitive processes of the learner, as they actively question, research, construct answers, communicate, present and lead discussion (Stanberry \& Azria-Evans, 2001). This approach has gained considerable traction in the primary and elementary school years, however, its active and integrated nature makes it problematic at the post-secondary level, which continues to function in separate disciplines (Steele \& Ashworth, 2013). Moreover, not all learners are comfortable with the transaction orientation, believing that they cannot learn from their peers, rather considering their professors/instructors to be the superior source of authoritative information (Stanberry \& Azria-Evans, 2001).

The goal of the transformation orientation is to raise social awareness and to bring about personal change in beliefs and behaviours (Cervatiue \& Ricento, 2012); it is holistic and spiritual in nature (Russell, 1997), recognizing the world as more than the sum of its parts (Hutchison \& Bosacki, 2000). The transformation approach demands reflection, (re)visioning of viewpoints, and critiquing assumptions; the educator gives up power/superiority in favour of a shared learning experience. "Learning is vicarious, collective, and personal." (ibid., p. 649) Learning strategies employed would include simulations, debates, studying critical incidents, and researching critical issues.

Cervatiue and Ricento (2012) maintain that the curriculum orientation taken by the educator is a reflection of their beliefs about the purpose and necessary approaches to education. However, educators and learners need not be tied to only one curriculum orientation, since each brings benefits to a learning opportunity (Russell, 1997; Stanberry \& Azria-Evans, 2001)

\subsection{Teaching/Learning via Social Media in Egypt}

The use of social media is quite common in Egypt, possibly because it was the first Arab country to use those media, especially (Alhayat.com). A 2015 public survey run by EMarketing Egypt Company showed that $73 \%$ of Facebook users in Egypt cannot imagine life without the Internet.(Note 1)

Education in Egypt is no exception, with conferences on distance learning using social networks in teaching/learning. For example, since 2013 Beni-Suef University has hosted an annual conference on distance learning, where studies on learning via different social networks are presented. There is also research exploring the effect of using social networks particularly in educational technology courses at faculties of education in Egypt. For example Shamah (2015) used Facebook in developing professional diploma students' educational programming skills. Abdelrazek (2011) explored the effect of computer teachers' interactions through social networks in developing their cognitive and performance skills. In his Ph.D thesis, Darweesh (2012) adopted social networks in developing education technology postgraduate students' problem solving skills and their attitudes towards learning via webs. Elmasrey (2012) illustrated that using Facebook developed student teachers' competencies in designing and producing learning websites, and sharing knowledge skills. Specific to science education, a master's level research study (Elkadey, 2012) addressed the effect of using cooperative learning through social networks in developing preparatory school students' science achievement and retention of learning. However, there is a gap in the research focusing on the use of social media in teaching/learning science issues for students or teachers, especially in an Egyptian context.

\subsection{Contemporary STSE}

Science teaching and learning have been significantly impacted by the perspective that the studies of science and technology are inescapably linked to social and environmental issues, commonly referred to as STSE. "It (STSE) places science squarely within social, technological, cultural, ethical, and political contexts." (Pedretti \& Nazir, 2011, p. 602). Pedagogies associated with STSE generally embed science content and skill learning within authentic contexts that lend themselves to critical discussion and problem solving (Aikenhead, 1988; Pedretti et al. 2008). STSE is considered a way for students to make meaning of science in their everyday lives.

Traditional science studies tend toward lectures and rote learning, with appended laboratory work generally reconstructing classical 'experiments', an apt example of the transmission orientation (Miller \& Seller, 1990). In contrast, STSE is considered to be potentially transactional and transformative as it places the teacher as facilitator and guide for students' active inquiries into science. In their review of STSE over the last four decades, Pedretti and 
Nazir (2011) point out that, although STSE has become popular around the globe (with research undertaken in places as diverse as the UK, the Netherlands, Canada, Japan, Taiwan, Australia, Israel, and Nigeria), still there is no single version of STSE that ultimately defines it. Thus, STSE is understood and enacted in multiple forms.

Pedagogies generally associated with STSE tend to be student-oriented and collaborative - that is, students are often involved in individual or group projects that require them to pursue science knowledge and skills, to be intellectually active (Aikenhead, 1988), to develop their reasoning skills through discourse (Zeidler, Sadler, Simmons \& Howes, 2004), to hone their skills of interdependence and communication (Aikenhead, 1988), as they address issues arising from everyday problems that are meaningful to them (Barrett \& Pedretti, 2006; Kozoll \& Osborne, 2004).

\subsection{STSE in Egypt}

Both school science and non-science textbooks in Egypt have been recently enriched with STSE issues that can help students think critically about the relationship of science and technology within the Egyptian society and environment in which they live. Consequently, the notion of designing courses based on the interconnections between STSE in Egypt has been addressed by a number of research studies exploring the development of students' environmental awareness (e.g. Yousef, 2012; Jad, 2010; Azouz 2007), critical thinking (Abou Hamed, 2014), and creative achievement (Deklijah, 2011).

These were preceded by other research studies on STS(Note 2) for students (Mohamed, 2009; Mohamed, 2008; Metwaley, 2005; Shetaiwey, 2005), as well as teachers (Mansour, 2010; Elsenouse, 2003; Zaytoun, 1991). All of the studies established various positive learning outcomes achieved by adopting STS/E approaches in science curricula, however, the studies were based largely on traditional classroom pedagogies that did not involve learners in group-work or fieldwork, nor were learners given opportunities to examine and reflect on authentic local STSE issues.

At the university level, science education courses for pre-service teachers (PTs) in Egypt focus on providing scientific knowledge, not on developing awareness and attitudes towards STSE issues, nor on implementing STSE studies in their future classes. The promotion of an STSE perspective in teacher education programmes in Egypt is not widespread, currently confined to individual research efforts at faculties of education (Elsenouse, 2003; Abd-El-Aal, 1998; Farrag, 1992; Mohamed, 1987), but not by educational associations that could leverage improvement in the practice of education in Egypt. Mansour (2010) claims that "unless curriculum developers take account of teachers' beliefs and knowledge and the sociocultural factors that shape or influence those beliefs in designing and planning new STS curriculum materials, these materials are unlikely to be implemented according to their intended plan" (p. 513). Za'rour (1987) showed that teachers could actually hinder the introduction of an STS education in schools if they are not prepared to teach it.

\section{Context for the Research}

\subsection{The Issue}

At Beni-Suef University in Egypt, as part of their education studies, PTs are required to take a course called Scientific Education. As the PTs are non-science students, the course is intended to develop the PTs' awareness of science, and the impact of science within society. One of the researchers was assigned to be the instructor of the course. Upon entering the classroom, and seeing the PTs sitting individually in rows, with the males separated from the females by two rows, the instructor became curious about the learning strategies employed by the PTs.

In a pilot study, she asked the PTs to describe how they learned the subjects at their faculty, particularly if there was any form of cooperation or interaction between them. Their written responses indicated that the only form of cooperation focused on "collecting money to photocopy or buy a (required) note/book". During semi-structured interviews, PTs revealed that they had never worked in groups; subjects were mainly delivered through lectures. When asked whether or not they had an account in any social media, the PTs indicated that they had a group on Facebook which they used with pseudonyms, just to inform each other of postponed lectures, dates for submitting assignments, etc.. Moreover, the female PTs mentioned that they never talked to their male colleagues during classes, explaining that there was "no reason or need to deal with them". (Note 3) It appeared that cooperation and interdependence amongst the PTs was infrequent.

The results of the pilot study encouraged the instructor/researcher to think deeply about how she could adopt an active approach in teaching the science education course such that PTs would be encouraged to interact and learn from each other cooperatively, rather than in isolation. 


\subsubsection{Alternative Pedagogy}

The restructured science course was designed in such a way that the PTs had to interact and cooperate within and amongst groups. The PTs were required to form working groups (of nine or ten) of their own choosing, and to register on a single class Facebook page using their real names, not pseudonyms. The administrator of this group was one of the PTs; all of the PTs as well as both authors were accepted as 'friends'. The PTs were guided by the instructor/researcher in their tasks mainly via Facebook, which they voted to call "Science Education for Life".

The groups were required to choose an STSE issue to study, and then present to the class. The list of suggested STSE issues consisted of: nuclear energy, hospital wastes, genetic engineering, biological weapons, agricultural wastes, urban sprawl, ozone depletion, electronic wastes, plastic products and antibiotics. Further, PTs were provided instructions to organize their groups according to various tasks, and to be aware of developing relationships both within their groups, as well as with other groups. For example, the PTs were asked to collaborate in collecting information about their STSE issues through conducting online research and through fieldwork. Collaboration among groups was encouraged in the form of information sharing through their Facebook Group. Every week during class time, each group made a presentation, which included photos, videos and evidence of their fieldwork, to demonstrate and elicit discussion about their STSE issue.

When asked to work in groups to collect information and work collaboratively on Facebook, the PTs were astonished and anxious. They were used to studying only the books their instructors assigned to them, yet in this alternative pedagogy they had to depend on themselves and each other to learn about the STSE issues, and to conduct fieldwork, both of which they felt they had "never done" before.

\section{Research Aims and Methods}

\subsection{The Research Questions}

This research investigated the effect of using Facebook and group fieldwork on the PTs' interdependence, and their awareness of specific STSE issues. Accordingly, the research phases addressed the following questions:

a. What is the effect of social media (Facebook) and group fieldwork on pre-service teachers' interdependence?

b. What is the effect of social media (Facebook) and group fieldwork on pre-service teachers' awareness of STSE issues?

c. What is the effect of social media (Facebook) and group fieldwork on pre-service teachers learning strategies and curriculum orientations?

\subsection{Methodology - Mixed Methods of Inquiry}

The use complementary multiple methods of data collection, known as triangulation, emphasizes the strengths and reduces the weaknesses of social research (Patton, 1990). Triangulation is "the process of using multiple data collection methods, data sources, analyses, or theories to check the validity of the findings" (Leedy, 1997, p. 169). Mixed-method inquiry in social science offers better understanding through: developing stronger validity, or credibility and less known bias; developing more complete and full portraits of our social world through the use of multiple perspectives; is more insightful, with new ideas, fresh perspectives, creative concepts and meanings, as findings diverge; and developing greater diversity of values and methods (Greene et al., 2005, p. 272).

Both quantitative and qualitative methods of data collection were used; the quantitative component comprises the pre- and post-STSE awareness and interdependence surveys, and the qualitative component is represented in the transcripts of Facebook and classroom discussions.

\subsection{Data Collection}

\subsubsection{The Participant Sample}

This study was conducted at the Faculty of Education, Beni-Suef University, Egypt, with 99 PTs (11 males and 88 females) enrolled in the Department of English, in year two in 2014. The PTs were enrolled in a course called Scientific Education, intended to develop their understanding of science knowledge and issues.

\subsubsection{Quantitative Data Collection}

The STSE Awareness Survey, which was developed by the first author, comprised 40 multiple choice questions aimed to study the PTs' knowledge and awareness of the ten proposed STSE issues before and after taking the 
Science Education course. See Appendix A, Sample STSE Awareness Survey.

The Interdependence Survey consisted of 45 statements under 3 main dimensions, classified into 12 sub-dimensions (Table 1). This survey, which aimed to identify the preferred level of interdependence of the PTs' during learning, (i.e. individual, cooperative or competitive learning) was adapted from a larger survey designed to investigate interdependence among university students in Egypt (Eljabrey \& Eldeib, 1998).

Table 1. Dimensions of the Interdependence Scale

\begin{tabular}{|c|c|c|}
\hline $\begin{array}{l}\text { Order of Statement in the } \\
\text { Scale }\end{array}$ & $\begin{array}{l}\text { Number of } \\
\text { Statements }\end{array}$ & Dimension \\
\hline \multicolumn{3}{|l|}{ A) Positive Interdependence: } \\
\hline $1,4,6,30,37,41$ & 6 & Helping Colleagues \\
\hline $11,24,31,33$ & 4 & Exchanging Knowledge \\
\hline $14,15,17,27$ & 4 & Sharing Aim \\
\hline $19,21,26$ & 3 & Being Responsible \\
\hline $9,23,39$ & 3 & Exchanging Dialogue \\
\hline $12,20,28$ & 3 & Accepting Colleagues \\
\hline 23 & & Total Number of Statements \\
\hline \multicolumn{3}{|c|}{ B) Negative Interdependence: } \\
\hline $5,7,13,18,32,34$ & 6 & Superiority \\
\hline 16,35 & 2 & Keeping Knowledge \\
\hline $36,38,43$ & 3 & Feeling Pleased with competition \\
\hline 11 & & Total Number of Statements \\
\hline \multicolumn{3}{|c|}{ c) Negative non-Interdependence: } \\
\hline $10,25,29,45$ & 4 & Self-dependence \\
\hline $22,40,42,44$ & 4 & Self-efficiency \\
\hline $2,3,8$ & 3 & $\begin{array}{l}\text { Abstaining from dealing with } \\
\text { colleagues }\end{array}$ \\
\hline 11 & & Total Number of Statements \\
\hline
\end{tabular}

Both the STSE Awareness Survey and the Interdependence Survey were administered to the PTs before the science course, and again at its end. The surveys took 20 and 15 minutes respectively and were in Arabic.

\subsubsection{Reliability and Validity of the Scales}

In order to evaluate the internal consistency reliability of the two scales, the Cronbach's Alpha statistic was computed using SPSS. Table 2 shows the values of Alpha for each dimension of the Independence Scale individually, and its validity:

Table 2. Values of Reliability and Validity of the Dimensions of the Interdependence Scale

\begin{tabular}{lll}
\hline Dimension & $\begin{array}{l}\text { Reliability: } \\
\text { Cronbach's Alpha }\end{array}$ & $\begin{array}{l}\text { Correlation factor as indicator of } \\
\text { validity }\end{array}$ \\
\hline A) Positive Interdependence & & \\
Helping Colleagues & 0.88 & 0.66 \\
Exchanging Knowledge & 0.87 & 0.65 \\
Sharing Aim & 0.85 & 0.60 \\
Being Responsible & 0.86 & 0.63 \\
Exchanging Dialogue & 0.87 & 0.60 \\
Accepting Colleagues & 0.88 & 0.62 \\
B) Negative Interdependence & & \\
Superiority & 0.80 & 0.58 \\
Keeping Knowledge & 0.83 & 0.54 \\
Feeling Pleased with competition & 0.82 & 0.60 \\
c) Negative Non-Interdependence: & & \\
Self-dependence & 0.84 & 0.57 \\
Self-efficiency & 0.84 & 0.61 \\
Abstaining from dealing with colleagues & 0.86 & 0.64 \\
\hline
\end{tabular}


The reality of the STSE scale was measured using correlation factor where its value was 0.89 which refers to a highly reliable scale. Also, the correlation coefficients of the score of every question in the STSE scale and its whole score ranged between 0.42 and 0.79 , which all are high and efficient at level 0.01 .

\subsubsection{Qualitative Data Collection}

The qualitative methods of data collection took place in three phases:

a. The PT's fieldwork, wherein groups of PTs took photos and conducted semi-structured interviews with people related to their STSE issue. Some interviews were video-recorded, others were audio-recorded according to the interviewees' desire. The information was submitted by the PTs via Facebook. The recorded and text data was initially collected in Arabic, and have been transcribed and then translated from Arabic to English by the first author.

b. The PTs' conversations on Facebook provided qualitative data that reveals how the PTs saw their experience with the science course at the beginning, during and by the end.

c. In addition, the instructor took notes of the PTs' discussions in the class.

Methodological triangulation was employed in the pilot study as well as the main study.

In the main study, triangulation was achieved using the two surveys, the fieldwork and scientific knowledge collected and submitted by the PTs, the PTts' conversations on Facebook, and the instructor's notes.

\section{Results and Discussion (Research Data Analysis)}

Discourse analysis was used in the analysis of qualitative data, to interpret the PTs' social interactions on Facebook, their narratives obtained during the fieldwork they conducted, their presentations, and their weekly class discussions. The Statistical Package for Social Studies (SPSS) was employed to analyze and explain quantitative data obtained from the surveys.

\subsection{Analyzing Data from the Pre- and Post-Interdependence Scale}

\subsubsection{Quantitative Analysis for Positive Interdependence}

Table 3 illustrates that the PTs' score means in all sub-dimensions of the post-interdependence scale increased compared with their score means in the pre-interdependence scale, indicating that positive interdependence among the PTs developed after their group fieldwork and use of Facebook. Positive interdependence developed not only between PTs in the same group, but also between PTs in different groups.

\subsubsection{Qualitative Analysis of Positive Interdependence}

In each group, the PTs chose a leader who was responsible for organizing meetings, dividing work into tasks, and distributing the tasks to group members.

I'm the leader of the group working on genetic engineering, I've spoken to my team, everyone has chosen the task she can do...I myself chose to share in our group fieldwork... Leader of Science Era Group (Facebook post)

An example of cooperation/interdependence between PTs in the same group occurred in a group of 10 female PTs tackling the topic of hospital wastes. The PTs divided the tasks amongst themselves: some visited a general hospital and took pictures showing unsafe medical waste disposal, some collected videos from the Internet, others collected articles on medical wastes, and two PTs made posters explaining the proper way to dispose of medical wastes generated at home. All data they collected were posted on their Facebook group before presenting in the class.

Cooperation also occurred between groups through the exchange of articles, videos, photos, ideas, etc. Below are three examples of cooperation and interdependence between groups.

Example One: (Facebook post)

My colleagues, can anybody tell us how can we find academic sites?...We've got too many sites, but we don't know which ones are academic. PT1

The web addresses of academic sites usually end with ac, org, ed, foun, as... PT2

Which issue are you studying? Let me know and I can send you some academic websites. PT3

Please DO NOT depend on Wikipedia...It's not an accurate academic source. PT3 
Table 3. PTs' Score Means in the Pre- and Post-Interdependence Scale

Paired Samples Statistics

\begin{tabular}{|c|c|c|c|c|c|}
\hline & & Mean & $\mathrm{N}$ & $\begin{array}{l}\text { Std. } \\
\text { Deviation }\end{array}$ & $\begin{array}{l}\text { Std. Error } \\
\text { Mean }\end{array}$ \\
\hline & First: Interdependence Scale Result & 8.19 & 99 & 1.113 & .112 \\
\hline \multirow{3}{*}{ Pair 1} & A) Positive Interdependence & & & & \\
\hline & Helping Colleagues (Pre-test) & & & & \\
\hline & Helping Colleagues (Post-test) & 16.14 & 99 & 1.818 & .183 \\
\hline \multirow[t]{2}{*}{ Pair 2} & Exchanging Knowledge (Pre-test) & 5.07 & 99 & .773 & .078 \\
\hline & Exchanging Knowledge (Post-test) & 11.16 & 99 & 1.076 & .108 \\
\hline \multirow[t]{2}{*}{ Pair 3} & Sharing Aim (Pre-test) & 4.77 & 99 & .697 & .070 \\
\hline & Sharing Aim (Post-test) & 10.82 & 99 & 1.335 & .134 \\
\hline \multirow[t]{2}{*}{ Pair 4} & Being Responsible (Pre-test) & 3.43 & 99 & .556 & .056 \\
\hline & Being Responsible (Post-test) & 8.33 & 99 & .881 & .089 \\
\hline \multirow[t]{2}{*}{ Pair 5} & Exchanging Dialogue (Pre-test) & 3.36 & 99 & .483 & .049 \\
\hline & Exchanging Dialogue (Post-test) & 8.07 & 99 & 1.136 & .114 \\
\hline \multirow[t]{2}{*}{ Pair 6} & Accepting Colleagues (Pre-test) & 3.40 & 99 & .513 & .052 \\
\hline & Accepting Colleagues (Post-test) & 8.22 & 99 & .815 & .082 \\
\hline \multirow[t]{2}{*}{ Pair 7} & Total Score of Positive Interdependence (Pre-test) & 28.19 & 99 & 2.613 & .263 \\
\hline & Total Score of Positive Interdependence (Post-test) & 62.53 & 99 & 4.672 & .470 \\
\hline \multirow{3}{*}{ Pair 8} & B) Negative Interdependence & 6.74 & 99 & .864 & .087 \\
\hline & Superiority (Pre-test) & & & & \\
\hline & Superiority (Post-test) & 12.81 & 99 & 2.436 & .245 \\
\hline \multirow[t]{2}{*}{ Pair 9} & Keeping Knowledge (Pre-test) & 5.57 & 99 & .731 & .073 \\
\hline & Keeping Knowledge (Post-test) & 2.34 & 99 & .688 & .069 \\
\hline \multirow[t]{2}{*}{ Pair 10} & Feeling Pleased with competition (Pre-test) & 3.21 & 99 & .411 & .041 \\
\hline & Feeling Pleased (Post-test) & 7.51 & 99 & 1.320 & .133 \\
\hline \multirow[t]{3}{*}{ Pair 11} & Total Score of Negative Interdependence (Pre-test) & 15.52 & 99 & 1.273 & .128 \\
\hline & Total Score of Negative Interdependence (Post-test) & 22.66 & 99 & 3.435 & .345 \\
\hline & C) Negative non-Interdependence & & & & \\
\hline \multirow[t]{2}{*}{ Pair 12} & Self-Dependence (Pre-test) & 10.91 & 99 & .608 & .061 \\
\hline & Self-Dependence (Post-test) & 4.47 & 99 & 1.003 & .101 \\
\hline \multirow[t]{2}{*}{ Pair 13} & Self-Competency (Pre-test) & 10.89 & 99 & .621 & .062 \\
\hline & Self-Competency (Post-test) & 4.33 & 99 & .892 & .090 \\
\hline \multirow[t]{2}{*}{ Pair 14} & Abstaining from Dealing with Colleagues (Pre-test) & 8.65 & 99 & .480 & .048 \\
\hline & Abstaining from Dealing with Colleagues (Post-test) & 3.51 & 99 & .720 & .072 \\
\hline \multirow[t]{2}{*}{ Pair 15} & Total Score of Negative non interdependence (Pre-test) & 30.44 & 99 & 1.099 & .110 \\
\hline & Total Score of Negative non interdependence (Post-test) & 12.34 & 99 & 2.051 & .206 \\
\hline
\end{tabular}

Example Two: When a group of PTs studied the use of plastic products, titling their study "You and Plastic World", the items they submitted through Facebook included a video on the ill effects of plastic wastes on the environment. As that video was in English PTs from other groups sent them three videos in Arabic related to their topic.

Thank you all for the videos you have posted. PT1

It's OK...I thought we all need to watch another video in Arabic...it's easier to understand what it talks about... PT2

Example Three: A group of 11 female PTs, who called their study "New Life", addressed the issue of urban sprawl, which they considered "a big problem that everyone can notice in her/his village". When the villagers they met refused to be interviewed, two male PTs sent posts offering to help them meet with farmers in their own villages.

Do not worry my colleagues. You can interview my uncle, if you want. PT1

No problem...I asked my neighbors and they don't mind...Just tell me when you would like to meet them. PT2 


\subsubsection{Quantitative Analysis for Negative Interdependence}

Table 3 shows that the PTs' score means in two sub-dimensions of the post-interdependence scale, superiority and feeling pleased with competition, increased. However, the third sub-dimension, keeping knowledge, decreased. Thus, we surmise that both the PTs' sense of superiority and their enjoyment of colleagues' competition developed as a result of their studies based on group fieldwork and Facebook interactions.

Table 4. Values of Effect Size $\eta$ of Using Facebook and Group Fieldwork on PTs' Interdependence

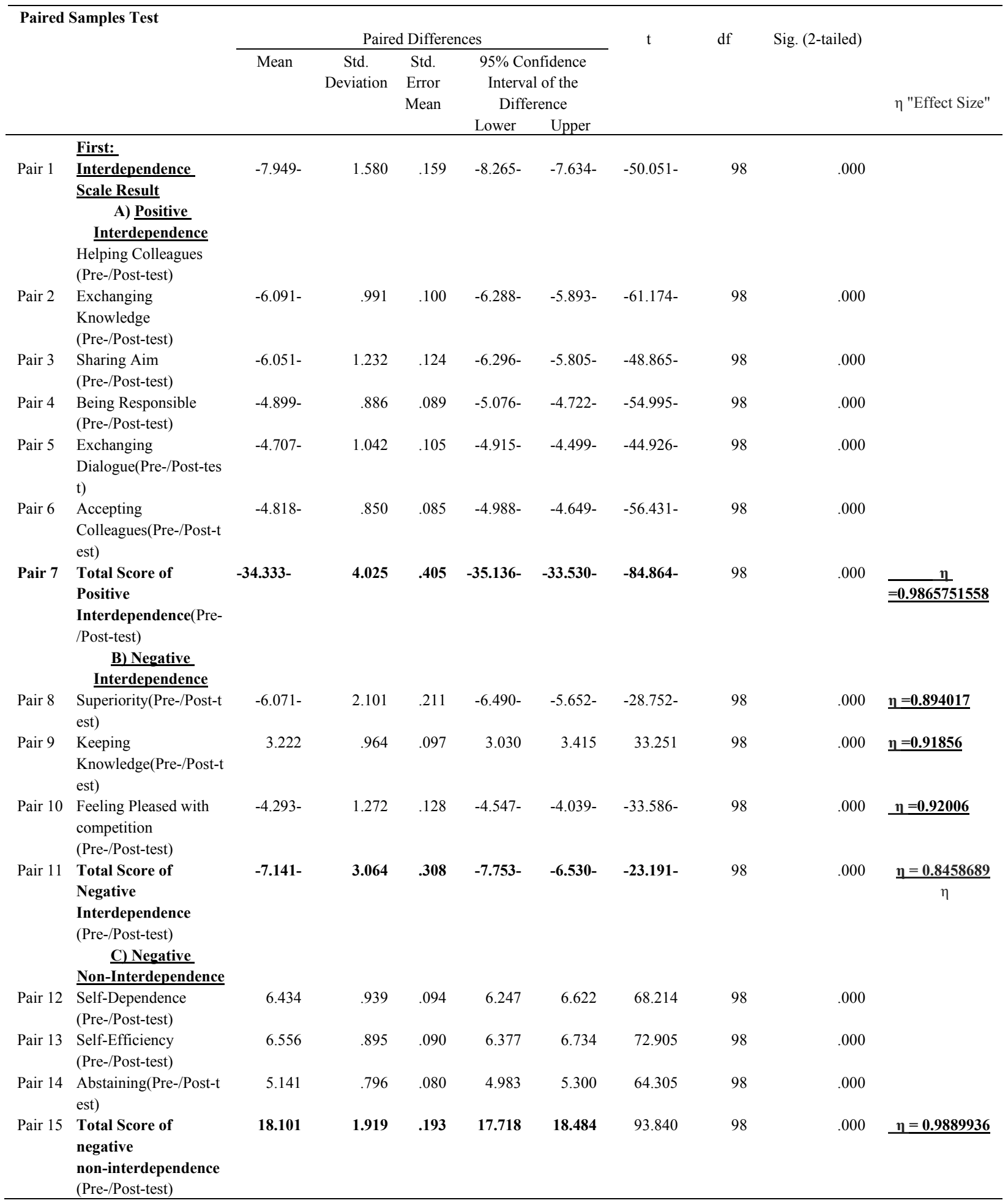


As shown in Table 4, this result was revealed also from the statistical treatment of the interdependence scale which measured the "Effect Size: $\eta=0.894$. The big value of $\eta$ indicates a very strong effect of both group fieldwork and Facebook on the PTs' sense of superiority.

We do not take the designation of 'competition as negative interdependence' to imply that competition is counterproductive to the end goal(s) of the PTs. In labeling feelings of superiority and feeling pleased with competition as 'negative interdependence' we are simply making the distinction between working together towards a goal versus working independently. We recognize the impetus that friendly competition might provide as groups worked together and separately. Indeed, the data clearly show that while every group competed with other groups in submitting their assignments, nonetheless the different groups helped each other to achieve those same ends.

\subsubsection{Qualitative Analysis of Negative Interdependence}

The qualitative data affords a number of examples of negative interdependence within and amongst the PT groups.

Example One: During a session, the instructor noticed a group of female PTs talking to each other loudly. She looked at them but did not comment, later receiving the following apology:

Sorry Dr. about what happened in the class. We were shouting at each other because our team hasn't finished the fieldwork yet! We decided to submit our assignment earlier than other groups but not to be the last one. PT New Life

Example Two: A group of nine PTs who called their study of genetic engineering "Science Era" posted their ideas on Facebook, generating a response from a group of ten PTs studying biological weapons, who called their issue "For Pure Environment". Their Facebook exchange reveals an element of competition.

What do you mean by biological weapons? PTI

It's the issue we've chosen to tackle...we're going to present it shortly... PT2 For Pure Environment

...please don't reveal what we are doing until we finish it... We're working hard to be the first on finishing our study... PT3 For Pure Environment

However, along with the desire to be first, there was also a collegial element: the group studying biological weapons shared their research with the group studying genetic engineering and asked them to comment. They exchanged information and discussed how science and technology can "destroy humans and environment".

\subsection{Analyzing Data for Individuality}

\subsubsection{Quantitative Analysis of Decrease in PTs' Individuality(Note 4)}

Table 3 illustrates that the PTs' score means in the three sub-dimensions, self-dependence, self-competency, and abstaining from dealing with others, as elements of post-negative non-interdependence, decreased in comparisons of pre- and post-tests. This implies a positive effect of using Facebook and group fieldwork in developing the PTs' interdependence, as well as decreasing their 'individuality'. That is, the PTs showed a strong tendency towards working collegially, rather than separately from each other.

\subsubsection{Qualitative Analysis of Decrease in PTs' Individuality}

The following posts from Facebook illustrate the increase of PTs' interdependence.

Hello my colleagues, I would like first to congratulate the 2 groups on their wonderful presentations at the class, they are an example of diligence and cooperation...Also I would like to say that I never thought to work in a group or to know what or how others work...but now I like teamwork... We [she and colleagues]'ve been close to each other...Thanks Dr. .PT1

To be honest, we, even males, never depended on each other in learning any subject...we never accepted others' ideas because we were learning as individuals, but now we all learn from each other. PT2

You're right, even females had not dealt with each other like now!...I myself thought that only my effort is enough to achieve success...but now I've found that I need to exchange what I know with my colleagues'... We all need WE. PT3

"Excellent...We all need WE." PT4 


\subsection{Tackling STSE issues collaboratively and PTs' Awareness of STSE Issues}

As listed in 3.1.1. the STSE issues suggested for study were: nuclear energy, hospital wastes, genetic engineering, biological weapons, agricultural wastes, urban sprawl, ozone depletion, electronic wastes, plastic products and antibiotics. The analysis of the survey data, and Facebook and classroom transcripts illustrate the PTs' learning.

\subsubsection{Quantitative Analysis of PTs' Awareness of STSE Issues}

Table 5 shows that there was a difference in the PTs' score means in the pre- and post-STSE scale in favor of the latter. This implies that the PTs became more aware of the STSE issues after the science education course. Table 6 refers to the big effect $(\eta=0.9836233187)$ of both group fieldwork and Facebook in developing the PTs' awareness of the STSE issues they studied.

Table 5. PTs' Score Means on the STSE Scale

\begin{tabular}{lllll}
\hline STSE Awareness test Result & Mean & N & Std. Deviation & Std. Error Mean \\
\hline STSE Awareness (Pre-test) & $\mathbf{9 . 1 8 1 8}$ & $\mathbf{9 9}$ & $\mathbf{1 . 6 8 6 4 6}$ & $\mathbf{. 1 6 9 5 0}$ \\
STSE Awareness (Post-test) & $\mathbf{3 4 . 0 1 0 1}$ & $\mathbf{9 9}$ & $\mathbf{2 . 9 5 0 2 5}$ & $\mathbf{. 2 9 6 5 1}$ \\
\hline
\end{tabular}

Table 6. Evaluating Standard Deviation and Effect Size of PTs' Mean Score in the Pre- and Post-STSE Scale

\begin{tabular}{|c|c|c|c|c|c|c|c|c|c|}
\hline \multicolumn{10}{|l|}{ Paired Samples Test } \\
\hline & \multicolumn{5}{|c|}{ Paired Differences } & \multirow[t]{3}{*}{$\mathrm{t}$} & \multirow[t]{3}{*}{ df } & \multirow{3}{*}{$\begin{array}{l}\text { Sig. } \\
\text { (2-tailed) }\end{array}$} & \multirow[t]{2}{*}{$\underline{\eta}$ "Effect Size" } \\
\hline & \multirow[t]{2}{*}{$\overline{\text { Mean }}$} & \multirow[t]{2}{*}{$\begin{array}{l}\text { Std. } \\
\text { Deviation }\end{array}$} & \multirow[t]{2}{*}{$\begin{array}{l}\text { Std. Error } \\
\text { Mean }\end{array}$} & \multicolumn{2}{|c|}{$\begin{array}{l}\text { 95\% Confidence Interval of } \\
\text { the Difference }\end{array}$} & & & & \\
\hline & & & & Lower & Upper & & & & \\
\hline $\begin{array}{l}\text { STSE } \\
\text { Awareness } \\
\text { (Pre-/Post-test) }\end{array}$ & -24.82828 & 3.21996 & .32362 & 25.47049- & $-24.18607-$ & $-76.721-$ & 98 & .000 & $\eta=0.9836233187$ \\
\hline
\end{tabular}

\subsubsection{Qualitative Analysis of PTs' Awareness of STSE Issues}

The statistical increase in STSE awareness is supported by the PTs dialogues on Facebook. Below we provide one example from each working group. The examples have been chosen to demonstrate the PTs' developing understanding of STSE issues. (Of added interest are the recurring comments that put the onus for responsible decision-making on scientists and government).

Nuclear Energy. The PTs hit on a number of disadvantages of using nuclear energy, and then consider the cost nationally, as well as suggesting an alternative local energy source.

NO [to nuclear energy]...we have to keep our environment clean. PT1

...but nuclear energy is useful as well...in medicine and increasing and improving plants and animals... PT2

Of course NO [for nuclear energy]. What about the leakage of nuclear wastes over time? How can scientists control these wastes? How much does that cost a developing country like Egypt? PT3

Hospital and medical wastes. In this example, the PTs ponder various ways to eliminate hospital and medical waste, given their toxicities. They understand the dangers of various methods of elimination, and recognize the value of looking outside their own borders (though not to America) for answers. The PTs are becoming more aware of the relationship between science, technology and environment, and the difficulty of finding a balance between them. The PTs collaborate with others not in their working group.

I think hospitals should be built away from houses in order to avoid the accumulation of their wastes in the places where we live. $P T 1$

...the big problem is how government gets rid of hospital wastes...burning the wastes is not a solution, but it causes other environmental problems. PT2

What about other countries my colleagues? Egypt is not the only country which has hospital wastes! We can learn from others, who agrees? PT3

What about burying the [hospital] wastes in the desert? PT4 
... hospital wastes may contain chemical or/and radioactive substances that can leak through underground water or something like that. PT5

Genetic Engineering: In this example PTs voice the complexity of the costs and benefits of genetic engineering.

Science and technology seem to have two opposite sides! Genetic engineering helps scientists produce insulin....but it increases the opportunity of deformation... PTI

It also decreases the genetic diversity. PT2

Although genetic engineering helps in planting some desert lands, it's been used in producing biological weapons as well. PT3

Biological Weapons: The PTs' demonstrate their awareness that science and technology can have damaging effects on environments, humans, animals and plants. Again, PTs from different groups join the conversation.

Of course biological weapons not only destroy humans, but also animals, plants, soil, air, water...they are all affected as well! PT1 For Pure Environment

Of course, neighboring countries can be affected as well... spread of these microorganisms via air can destroy... PT2 For Pure Environment

So, instead of maintaining our environment clean, people use science and technology to make it worse! PT1

Agricultural Waste: The PTs demonstrate their understanding of the importance of using agricultural wastes as animal food and fertilizers, instead of burning them. They also reflect on how science and technology have decreased the use of agricultural wastes as a fuel in the Egyptian countryside. This excerpt, though somewhat lengthy, shows the PTs using both their personal experience, and their science knowledge to aid each other in a growing understanding of the arguable relationships within STSE.

...organic fertilizers are more useful than chemical substances farmers use these days.. PT1

...if organic fertilizers are more useful than the artificial ones, why then scientists have made the latter? PT2

I think farmers are just like any other people...they want to live in the era of science and technology. PT3

I am a villager and we use microwave and gas ovens in cooking...my grandma used an oven made from clay to bake bread...but these days we really need to use clean fuels in our life...that's what scientists provide us with...! PT4

I myself suffer from air pollution resulting from burning agricultural wastes in my area...I'm allergic to... I take medications. PT5

So, no more science and technology in the Egyptian countryside! PT6

I never meant that. We all need science and technology in our lives, but we also need nature... PT7

Antibiotics: For their study on antibiotics, the PTs interviewed pharmacists, uneducated people, and colleagues. Through discussion the PTs disseminated correct scientific information, and helped each other become aware of the side effects of using antibiotics: the health and environmental problems resulting from excessive use.

Flu is caused by a virus not by bacteria...antibiotics wouldn't help in this case. PT1 To Be Healthy

There is another issue...by the time the new generation of bacteria resists antibiotics...they wouldn't work. PT2 To Be Healthy

So, doctors should update their knowledge and be provided with the new active antibiotics. PTI

The excessive use of antibiotics is also harmful... PT2

Although antibiotics can be useful and cure some diseases, some people are allergic to those chemicals...some people may need penicillin, but it has side effects...diarrhea, dizziness, headache... PT3To Be Healthy

Sometimes scientists provide us with what hurt ourselves...it's intriguing! PT4 
We have got 2 cases. The first, the wastes resulted if we don't complete the course, the second the wastes resulted even when we take the entire antibiotics...chemicals, boxes, plastics or glass bottles, paper leaflets, etc. PT3

...The more we use antibiotics, the more environmental problems we struggle from... PT5

Use of Plastics: In this excerpt the PTs grapple with the pervasive use of plastic, a material that seems absolutely necessary to some of them although they are aware of the ill effects of their excessive use. The PTs examine society's relationship with plastic.

Plastic products are around us everywhere...we cannot escape them. PTI

If we manage to only use the safe plastic products, what about our plastic wastes...how do we really get rid of those wastes? Instructor

In my village, plastic wastes, e.g. bags and bottles are thrown on the side of the roads...then they move via wind into the soil and are buried. $P T 2$

One of the videos you posted shows how plastic wastes hurt soil and affect its fertility, which in turn affects our health. PT3

Some shopkeepers in my village burn their plastic wastes...This would cause other environmental problems and also hurt our health. PT4

I recently read that River Nile has been polluted by a big amount of plastic wastes, which threatens fish life and our health in turn. PT5

Then, the solution is we shouldn't use plastic products...in order to save ourselves as well as our environment. PT6

That's impossible! PT7

Why did scientists produce this substance if it has a bad effect on our health as well as our environment? PT8

I myself cannot get rid of my plastic accessories!...bracelets, earrings, necklaces...I like them. PT9

Communication Technology / Electronic Wastes: One group of PTs focused their research on communication technology as a source of e-wastes. They became aware of the side effects of their use of technological communication sets such as mobile phones, ipads, etc., on their time, health and environment. They called their study "Communication Technology...the Plague of our Era" because they felt that communication technology "has spread among people - young and old - rabidly just like a plague". They learned that "e-wastes resulting from smart phones have been increasing every day because those sets have been handled by people everywhere and many people, particularly the young ones who change their sets every year or every a few months".

In addition to library and Internet research, they interviewed two professors of medicine and sociology, and several students at the faculty. The PTs claimed that there is a need for "face-to-face communication" instead of what they felt was "addictive communication technology". However, their discussion in Facebook shows that they were extremely reluctant to switch off their own mobile phones for even a few hours a day.

The study you posted also refers to the importance of communication technology in our life. PT1

... but it also illustrates the danger of being slaves to communication technology such as mobile calls, social network. PT1 E-Waste

We've mentioned electronic, metal and plastic wastes. PT2

Also, the radiation caused by the battery pollutes the soil...and electromagnetic field when we use it. PT3

I've read that some people have got social problems by using social network. PT4

Now, can we switch off our phones/tablets for a few hours a day? Instructor

The challenge to turn off their phones was not successful. The PTs claimed that although they were "aware of the detrimental effects of communication technology", they "could not get rid of using it for a few hours a day"!

Urban Sprawl: The PTs studied the environmental and social problems produced by urban sprawl; what is meant by urban sprawl, its causes, and its effect on agricultural lands, climate, archeological places, economics, etc. Their interviews with farmers revealed that farmers sold their agricultural land to others who built houses or factories in it 
because "life is so expensive" and farmers "needed money in order to live a decent life", but "planting it won't provide them with enough money". Two farmers (A \& B) indicated that building factories on or near agricultural land has resulted in urban sprawl. However, they also pointed out that the factory provided jobs and raised the standard of living in the village. The PTs are opposed to urban sprawl on agricultural land, arguing that "laws have to be applied strictly and punishment must be increased on people who build houses or factories in agricultural land".

Some PTs asked villagers to reflect on the "new modern life" in their village, by questioning them about the side effects of industrial wastes on the environment in which they lived. The villagers articulate the dilemma, similar to that of other STSE issues which the PTs studied: science and technology carry benefits and costs.

...we know it's harmful if they throw it [factory wastes] in the agricultural land, but it's the government role to make control on these factories not ours. Villager $A$

Would you report any violations you see? PTI

It's not my business...We also need to live the new modern life...Our village has been civilized. Villager $A$

What do you mean by civilized? PT1

Do you think I'm illiterate? I'm educated and know that science and technology have been a part of our life. We live in the age of science and technology. Villager $B$

But what about the side effect of science and technology on our lives, OUR ENVIRONMENT? PT2

We cannot prevent this side effect. Villager $B$

Can we avoid it? Can we protect ourselves and our environment from it? PT2

NO...It's so difficult...otherwise we go back to the past...no electricity, no factories, no many things...impossible! Villager $B$

The Ozone Layer: In their study of the ozone layer and its effect on society and environment, this group interviewed 2 professors at the faculty of science, some colleagues in another department, and local people. In their assignment, they explained what ozone is, how it is created, and how human behaviours can destroy the ozone layer. On Facebook they first posted some questions asking colleagues about using pesticides, perfumes, air conditioners, the number of fridges and freezers at their houses, etc. The PTs' replies showed that they all use pesticides and perfumes, they have fridges and freezers, but only $68 \%$ of them had air conditioners at home. The group's informal survey challenged the PTs to consider their part in ozone depletion. They discussed the conflict between the products that science and technology provides humans and the side effects of those products on human health and environment.

I live in a village, there are lots of mosquitoes, so we use birosole [a kind of pesticides] to get rid of those insects. $P T 1$

I myself have to spray birosole in my bedroom twice a day in order to get rid of mosquitoes. PT2

Do you know that pesticides contain chlorine that destroys ozone layer? PT3 Ozone Group

We also cannot rid of our freezers or fridges, so we destroy our environment. PT3

I've read that ozone depletion causes the reduced immunity to many people! PT4

It's a big problem, we use pesticides to kill mosquitoes and in the same time we cause diseases to ourselves. PT5

It's the scientists who provide us with such equipment and substances that go against our health as well as our environment. PT6

\subsubsection{Understanding the Work of Scientists}

Throughout the data the PTs demonstrate a poor understanding of the political, economic and social pressures that impact the direction that scientists and engineers take in the research and development of knowledge and products. Numerous statements are made implying that scientists make individually-driven decisions (often with negative consequences) regarding the direction of their work, for example from the plastics conversation, "Why did scientists produce this substance if it has a bad effect on our health as well as our environment?" and "Unfortunately, from what we are studying, scientists have never given us a something perfect. They give us things that may help us enjoy 
our lives but also spoil our health and environment."

\subsection{Responses to Alternative Pedagogy}

While the research had not set out to explore the PTs' recognition and understanding of the alternative pedagogy in which they had participated, nonetheless, they provided insights in this area. The PTs appreciated the new experience although it was perceived as more difficult work than what they were used to. They recognize increased self-confidence, cooperation as a positive learning experience, a deeper understanding of the relationships between science, technology, society and environment, and an opportunity to think critically without memorization,.

For me although that way was difficult at first because I had never conducted fieldwork or cooperate with others to look for knowledge....but gradually I began to interact with my colleagues and exchange our work.

I think it's desirable to learn about things around us... things about what science and technology provide us...this would help us in dealing rationally with their applications. Also, I think we won't forget what we've learnt because we did it by ourselves through hard work we really enjoyed but not through memorization...

However, the PTs also identified disadvantages of the alternative pedagogy: a general dislike of group work, the amount of scientific knowledge amassed from the Internet and fieldwork, and the time it took to do so.

The way we have collected knowledge, from the Internet, interviewing professors and different people, videotaping and taking pictures, reading others' work and making comments on our Facebook group....all this has taken us too much time while we should study other courses.

I never like this way because you asked us to do teamwork which I really hate. I don't like to do things with others BUT I PREFER to depend on myself...I like doing things on my own without any help from any person even my brothers...

It is noteworthy that none of the PTs considered the use of group-work and cooperative learning strategies for their own future classes in which they would be the teachers.

\section{Discussion and Recommendations}

The research conducted in the Egyptian Faculty of Education Science Education course leads us to make several recommendations for the future instruction of PTs with regards to appropriate and powerful alternative pedagogies.

Curriculum Orientations: Alternative pedagogy, in the form of social media, group work and fieldwork as course requirements, created a strong emphasis on a transactional orientation for teaching and learning. The PTs were required to interact, share and critique information and ideas, and develop a sense of cooperation. This was a significant change in pedagogy for the PTs, but one that was (mostly) appreciated, and certainly resulted in significant increases in both their interdependence with each other, and their understanding of STSE issues. However, all three curriculum orientations are considered to be important (Russell, 1997; Stanberry \& Azria-Evans, 2001) at different times and stages of the learning process.

Recommendation \#1: Move towards incorporating all three orientations in teacher education both for the PTs' own learning experiences, and to model for future classrooms.

Recommendation \#2: Include more elements of group work as a way to reap the benefits of transactional learning, including interdependence/cooperation and deeper understanding of the topics being studied.

Social Media: Vygotsky (1978) considered learners' cognitive development to be a result of the "dialectical relationship" between the individuals and their social context. The learner has to be provided with "cognitive conflicts" through communication with others, so that s/he can achieve cognitive development and a higher quality of thinking (ibid). The PTs' many reflections and arguments on Facebook challenged their cognitive development and critical views on issues. The act of discussion via social media created numerous opportunities for transmission of knowledge, transaction of ideas, and contemplation of personal transformation in attitudes and behaviours. The latter emerged from time to time as evidenced by environmental citizenship 'thinking', though not perhaps 'doing'.

Involving the first author, and later the second author, in the PTs' Facebook group helped to achieve the aims of the proposed course, i.e. increasing PTs' STSE awareness and their interdependence. Using Facebook motivated the PTs to write feedback, reflections and arguments on the STSE issues. 
Recommendation \#3: Encourage the use of social media to support cognitive development through collegial contact with others.

Recommendation \#4: Encourage the use of social media as a way to support the development of environmental citizenship, as PTs challenge each others' attitudes and behaviours.

STSE Awareness: The PTs' science knowledge and their understanding of the complexities of STSE were considerably strengthened by group work, and the use of social networking. Indeed, a transactional orientation is key to effective STSE teaching and learning. An important element of STSE awareness is understanding the conflicts and complexities inherent in the STSE relationships. "Every time we discuss an issue, we have found out a sort of conflict between what scientific products are made for and their side effects on us and our environment." The course requirements within a transactional format provided a robust introduction to STSE issues for the PTs. In particular, the PTs might develop a better grasp of the nature of the work of scientists, as impacted by political, social, ethical and economic pressures. As PTs gain understanding, they might also realize how their own actions/agency could be leveraged to influence the direction of scientific research and development.

Recommendation \#5: Embed STSE studies within science courses for PTs and include a focus on scientists' work.

\section{Conclusion}

In Egypt, science classes in faculties of education tend to focus on traditional teaching methods that lead to rote learning without interaction between and amongst PTs and their instructors. In addition, those classes lack resources and activities that challenge PTs to critique their studies. This research was an endeavour to promote active learning where PTs depended on themselves and each other in the learning process, rather than receiving knowledge from their instructors. The PTs were given the opportunity to learn cooperatively via Facebook and the activities they conducted. Such cooperation facilitated their learning and helped them make friendships. They practised 'learning' by looking for knowledge, and conducting group fieldwork activities instead of getting ready-made books as directed by their instructors.

The recommendations are intended to increase the richness of the learning experiences for PTs studying in Egyptian faculties of education, to support them in realizing the complexities of science and science education, and to provide similar learning experiences for their future students. This will necessitate the involvement of teachers and students as citizens/community participants addressing issues and working together for a common goal, and will require a re-visioning and re-authoring of teacher education programmes in Egypt.

\section{Acknowledgements}

The authors would like to thank the PTs who participated in the study for their acceptance to study the proposed course, assistance in data collection and giving the authors their permission to publish the results.

\section{References}

Abd-El-Aal, W. M. M. (1998). The effect of a proposed programme in science education on student art teachers' science achievement and their scientific attitudes. (Unpublished M. Ed thesis) Beni-Suef: Cairo University, Beni-Suef Branch (In Arabic).

Abdelrazek, A. A. M. (2011). The effect of using different interactions in virtual training through social networks on developing cognitive and performance skills of computer teachers 'electronic lesson planning. Journal of Education Technology Studies and Research, 21(2), 211-216.

Abou Hamed, M. A. A. (2014). The effectiveness of using an educational program based on the integration of Science, Technology, Society and Environment Approach (STSE) in teaching Science for preparatory school pupils to develop their critical thinking skills, scientific attitudes and retention of learning. (Unpublished PhD thesis) Faculty of Education, El Menya University (in Arabic).

Aikenhead, G. S. (1988). Teaching science through a science-technology-society-environment approach: An instruction guide. SIDRU Research Report 12. Regina University, Saskatchewan Instructional Development and Research Unit.

Azouz, M. M. (2007). The Effect of using STSE in teaching the environmental science course in developing secondary school students' environmental awareness and science processes. (Unpublished M.Ed. thesis) Faculty of Education, Beni-Suef University (in Arabic). 
Barrett, S. E., \& Pedretti, E. (2006). Contrasting orientations: STSE for social reconstruction or social reproduction. School and Science Mathematics, 106(5), 237-247. https://doi.org/10.1111/j.1949-8594.2006.tb18082.x

Cervatiue, A., \& Ricento, T. (2012). Curriculum meta-orientations in the language instruction for newcomers to Canada program. The Canadian Journal for the Study of Adult Education, 12(2), 17-31.

Darweesh, A. M. M. (2012). The Effectiveness of using some learning styles through a social network environment in developing education technology postgraduated students' problem solving skills and attitudes towards learning via webs. (Unpublished $\mathrm{PhD}$ thesis). Faculty of Education Helwan University.

Deklijah, W. A. (2011). The effect using STSE approach in developing secondary school students' scientific culture and creative achievement in physics. (Unpublished M. Ed. thesis) Faculty of Education, Kafrelsheikh University (in Arabic).

Eljabrey, A. A., \& Edeib, M. M. (1998). Psychology of Cooperation, Competition and Individuality. Alam El-Kotob, Cairo (In Arabic).

Elkadey, S. T. A. (2012). The effect of using some cooperative learning strategies in social networks on developing preparatory school pupils' science achievement and retention of learning. (Unpublished M.Ed. thesis). Faculty of Education Helwan University (in Arabic).

Elmasrey, S. F. M. (2012). The effect of using Facebook in presenting the educational content on student teachers' acquirement of the competencies of designing and producing learning websites and sharing knowledge skills. Journal of Education Technology- Studies and Research, 22(3), 165-222.

Elsenouse, H. (2003). Effectiveness of a proposed programme in the view of integration of science, technology and society (STS) for enhancing the scientific literacy of pre-service primary science teachers at faculties of education. (Unpublished M.Ed. thesis) Beni-Suef: Cairo University, Beni-Suef Branch (In Arabic).

Farrag, M. H. (1992). The relationship between science teachers`scientific literacy and science achievement and scientific thinking of preparatory school pupils. (Unpublished M. Ed. Thesis) Cairo: Ain Shams University, Faculty of Education (In Arabic).

Greene, J.C., Kreider, H., \& Mayer, E. (2005). Combining qualitative and quantitative methods in social inquiry. In B. Somekh and C. Lewin (Eds.), Research Methods in the Social Sciences, (274-281), London: Sage Publications. $\quad$ Retrieved from http://www.shorouknews.com/news/view.aspx?cdate=24062015\&id=88f20e8d-1 fa6-4f29-bdf5-eed06446f7a 1

Hutchison, D., \& Bosacki, S. (2000). Over the edge: Can holistic education contribute to experiential education? The Journal of Experiential Education, 23(3), 177-182. https://doi.org/10.1177/105382590002300310

Jad, A. L. M. (2010). The effect of a proposed science programme in developing preparatory school pupils' awareness of STSE issues. (Unpublished PhD thesis). Faculty of Women, Ain Shams University (in Arabic).

Kozoll, R. H., \& Osborne, M. D. (2004). Finding meaning in science: Lifeworld, identity, and self. Science Education, 88, 157-181. https://doi.org/10.1002/sce.10108

Leedy, P.D. (1997). Practical Research: Planning and Design (6th ed.). New Jersey: Merill

Mansour, N. (2010). The impact of the knowledge and beliefs of Egyptian science teachers in integrating an STS based curriculum. Journal of Science Teacher Education, 21(5), 513-534. https://doi.org/10.1007/s10972-010-9193-0

Metwaley, Z. A. (2005). The effectiveness of a proposed STS- based programme on teaching science in one-class school, skills. (Unpublished Ph. D thesis ) Faculty of Education, South Valley University, (In Arabic).

Miller, J. P., \& Seller, W. (1990). Curriculum perspectives and practice. New York: Longman.

Mohamed, A. A. E. (2009). The effect of using STS approach on primary pupils' science achievement and developing their hand skills. (Unpublished M. Ed. Thesis), Faculty of Education, Kafrelsheikh University, (In Arabic).

Mohamed, M. H. M. (1987). The effect of teaching the general science course on non-science student teachers' scientific attitudes. (Unpublished Ph.D. thesis), Faculty of Education, Alexandria University, (In Arabic).

Mohamed, N. J. A. (2008). The effect of using STS approach in teaching science on developing preparatory first year pupils' some properties of citizenship. (Unpublished M. Ed. Thesis), Faculty of Women, Ain Shams University (In Arabic). 
Patton, M.Q. (1990). Qualitative Evaluation Methods. Beverly Hills, CA: Sage Publications.

Pedretti, E., \& Nazir, J. (2011). Currents in STSE education: Mapping a complex field, 40 years on. Science Education, 95(4), 601-626. https://doi.org/10.1002/sce.20435

Pedretti, E., Bencze, L., Hewitt, J., Romkey, L., \& Jivraj, A. (2008). Promoting issues-based STSE perspectives in science teacher education: Problems of identity and Ideology. Science and Education, 17, 941-960. https://doi.org/10.1007/s11191-006-9060-8

Russell, C.L. (1997). Approaches to environmental education: Toward a transformative perspective. Holistic Education Review, 10(1), 34-40.

Shamah, M. A. (2015). The effectiveness of using Facebook as a learning environment in developing education technology vocational Diploma students' programming skills, the fifteenth scientific conference of the Egyptian Association for Educational Technology "Education technology: future visions", 28-29 Oct, Egypt.

Shetaiwey, A. A. (2005). Developing primary science curriculum in the light of STS approach. (Unpublished Ph. D thesis) Faculty of Women, Ain Shams University, (In Arabic).

Stanberry, A.M., \& Azria-Evans, M. (2001). Perspectives in teaching gerontology: Matching strategies with purpose and context. Education Gerontology, 27, 639-656. https://doi.org/10.1080/036012701317117884

Steele, Astrid \& Ashworth, Elizabeth L. (2013). Walking the Integration Talk: An ArtSci Project. The Canadian Journal for the Scholarship of Teaching and Learning, 4(2), Article 4.

Vygotsky, L. (1978). Mind in Society: The Development of Higher Psychological Processes. Cambridge MA: Harvard University Press.

Yousef, H. M. M. A. (2012). The effect of a developed geography curriculum based on STSE approach on developing preparatory school pupils' achievement and their environmental awareness. (Unpublished $\mathrm{PhD}$ thesis). Faculty of Women, Ain Shams University (in Arabic).

Za'rour, G. I. (1987). Forces hindering the introduction of STS education in schools, In K. Riquarts (Ed.), Science and Technology education and the quality of life (pp. 731-741). Kiel, Germany: Institute for Science education, Kiel University.

Zaytoun, K. A. (1991). Teachers' views on STS issues. Paper presented at the third scientific conference of The Egyptian Association for Curricula and Methodologies: Future views on Curricula in the Arab Nation, 4-8 Aug., Alexandria, Egypt, V(2), 699-722 (In Arabic).

Zeidler, D., Sadler, T., Simmons, M., \& Howes, E. (2004). Beyond STS: A Research-Based framework for socioscientific issues education. Science Education, 89(3), 357-377. https://doi.org/10.1002/sce.20048

\section{Notes}

Note1.http://www.shorouknews.com/news/view.aspx?cdate=24062015\&id=88f20e8d-1fa6-4f29-bdf5-eed06446f7a 1 on 25 Dec. 2015.

Note 2. STS (science, technology and society) was the forerunner of STSE, prior to the addition of environmental concerns.

Note 3. Although Egyptian universities (except Al Azhar University and Faculty of Women at Ain Shams University) are gender mixed, where male and female students learn in the same classes and are presumed to interact with each other and exchange views and ideas, the traditional education style in those classes hinders interactions that would positively affect their learning, as well as their interpersonal relationships.

Note 4. What is meant by 'individuality' here is the PTs' preference to learn individually but not with/from each other. The word individuality has been commonly used in the Egyptian scale designed by Eljabrey and Eldeib (1998) to describe the tendency and desire of students to learn on their own. 


\section{Appendix}

\section{Samples from the STSE Awareness Survey}

Burning medical wastes results in thick smoke that may contain:
a. cadmium and dioxin $\sqrt{ }$
b. calcium oxalates
c. iron and magnesium silicates
d. antioxidants

Chemicals from e-wastes:
a. are biodegradable
b. are not toxic for human beings
c. persist in the environment for long periods of time $\sqrt{ }$
d. do not include heavy metals

One biological treatment of organic plant wastes that prevent environmental pollution and produce organic fertilizer is:
a. partial burning of the wastes and then adding them to the soil
b. composting $\sqrt{ }$
c. the complete drying of the wastes and then using them as fertilizers
d. homogenized mixing with chemical fertilizer

The spread of GM crops threatens the environment in terms of:
a. loss of biodiversity $\sqrt{ }$
b. reduction of agricultural productivity
c. declining soil fertility
d. repeated mono-cropping

Ozone depletion results from the accumulation of one of the following in the stratosphere:
a. carbon dioxide gas
b. sulfur oxides
c. chlorofluorocarbons $\sqrt{ }$
d. carbon monoxide gas 